\title{
Karyomorphology of Five Morphotypes of Taro \\ (Colocasia esculenta (L) SCHOTT)
}

\author{
M. T. Sreekumari and P. M. Mathew \\ Department of Botany, University of Kerala, \\ Kariavattom, Trivandrum, India
}

Accepted November 2, 1990

Taro (Colocasia esculenta (L) Schott) is an important edible aroid whose tubers are used as staple food in many countries. Colocasia is believed to have originated in South Central Asia, probably India or Malayasia (Onwueme 1978). Innumerable varieties are known under cultivation in India which occur in two ploidy levels (Kuruvilla and Avtar Singh 1981), diploids with $2 n=28$ and triploids with $2 n=42$ chromosomes. Karyomorphological studies on cultivated taro is rather sparse (Kuruvilla and Avtar Singh 1981, Coates, et al. 1988, Sreekumari and Mathew 1989). Since this crop occurs in several morphologically distinct types, karyo-morphological information will be useful for evaluating the nature and degree of chromosomal difference, if any, that could be associated with plant morphological difference, in addition to the data yielding useful material for planning effective breeding programmes in this crop. This paper concerns detailed karyomorphology of five edible diploid morphotypes of taro.

\section{Materials and methods}

The morphotypes studied here were procured from different regions in India such as Malappuram, Alleppey and Trivandrum (Kerala State), Salem (Tamil Nadu State) and Bhubaneswar (Orissa State). They differed recognizably one from the other in respect of several morphological features, of which the difference in the rate of tiller production per plant, pigmentation on different plant parts, size and shape of leaf blade as well as tuber yield were striking. The Malappuram (Morphotype I) and Alleppeyy (Morphotype II) collections were profusely tillering (10-15 tillers/plant) and high yielding $(>850 \mathrm{~g} / \mathrm{plant})$ whereas the Trivandrum collection (Morphotype III) was medium tillering (5-7 tillers/plant) and medium yielding (350-450 g/plant) Morphotype IV (Salem Collection) was a low tillering type (2-3 tillers/plant) with poor tuber yield $(<250 \mathrm{~g} /$ plant). The Bhubaneswar collection (Morphotype V) showed profuse tillering and low yield. The aerial plant parts of Morphotype I and II were all green except for a purple spot at the leaf-petiole junction in the latter. In Morphotype III, the base of leaf sheath and distal region of petiole were purple with the region in between being green in colour. In Morphotype IV, the leaf sheath and petiole were light purple throughout while in Morphotype $\mathrm{V}$ this was deep purple. Morphotype $\mathrm{V}$ was characterised by strikingly narrow leaves with their margin undulated.

Somatic chromosomes of the above morphotypes were studied from root tips fixed in $3: 1$ Carnoy's fluid after pretreatment with $0.002 \mathrm{M} 8$-Hydroxyquinoline at $4^{\circ} \mathrm{C}$ for $2 \mathrm{hr}$ and stained in acetocarmine. Karyomorphology was studied based on measurements from ten well spread metaphase plates of compareable stage. Karyotype analysis was made following the system proposed by Levan et al. (1964) and karyotype asymmetry determined after Stebbins (1958). The TF\% was calculated following Huziwara (1962). For constructing karyotype formula, chromosome lengths were classified under three size groups ( $\mathrm{A}, \mathrm{B}$ and $\mathrm{C}$ ) such as $\mathrm{A}=3.99$ 
$3.0 \mu \mathrm{m}, \mathrm{B}=2.99-2.0 \mu \mathrm{m}$ and $\mathrm{C}=1.99-1.0 \mu \mathrm{m}$.

\section{Observations}

Root tip cells of all the five morphotypes showed 28 chromosomes, and they ranged in length from 1.50-3.67 $\mu \mathrm{m}$. The karyotype was more or less symmetrical and less specialized ( $2 \mathrm{~A}$ and $2 \mathrm{~B}$ ). The karyomorphological features are summarised in Table 1 .

In Morphotype I the karyotype was of ' $2 \mathrm{~A}$ ' type and consisted of 10 pairs of $\mathrm{m}$ - and 4 pairs of sm-type chromsomes (Fig. 1). The chromosome pair 3 exhibited structureal heteromorphism for centromeric position. The karyotype of Morphotype II and III were strikingly similar (2B) with 8 pairs of $\mathrm{m}$-, $5 \mathrm{sm}$ - and 1 of st-type chromsomes (Figs. 2, 3). Chromosome No. 1 in the former, however showed size heteromorphism. Morphotype IV (Fig. 4) possessed 11 pairs of $\mathrm{m}-, 1 \mathrm{sm}$ - and 2 of st-type chromosomes in their somatic complement. The karyotype of Morphotype $\mathrm{V}$ was recognizably different from those of the others in centromeric positions of most of the chromsomes (Figs. 5,6). The somatic complement showed striking reduction in the frequency of $m$-type chromosomes and higher frequency of st-type chromosomes. One of the st-type chromosomes (No. 1) showed r-value of 6.28 as against less than in all the other morphotypes. The TF\% was also lowest.

Table 1. Karyomorphological details of five morphotypes of taro

\begin{tabular}{|c|c|c|c|c|c|}
\hline Morphotype & $\begin{array}{l}\mathrm{TCL} \\
(\mu \mathrm{m})\end{array}$ & $\begin{array}{l}\mathrm{ACL} \\
(\mu \mathrm{m})\end{array}$ & Karyotype formula & Category & $\mathrm{TF} \%$ \\
\hline I & 65.78 & 2.35 & $\mathrm{~K}(2 \mathrm{n}=28)=4 \mathrm{Am}+12 \mathrm{Bm}+8 \mathrm{Bsm}+4 \mathrm{Cm}$ & $2 \mathrm{~A}$ & 40.05 \\
\hline II & 74.32 & 2.65 & $\begin{aligned} \mathrm{K}(2 \mathrm{n}=28)= & 6 \mathrm{Am}+4 \mathrm{Asm}+10 \mathrm{Bm}+4 \mathrm{Bsm} \\
& +2 \mathrm{Csm}+2 \mathrm{Cst}\end{aligned}$ & 2B & 38.29 \\
\hline III & 70.82 & 2.53 & $\begin{aligned} \mathrm{K}(2 \mathrm{n}=28)= & 4 \mathrm{Am}+14 \mathrm{Bm}+6 \mathrm{Bsm}+2 \mathrm{Csm} \\
& +2 \mathrm{Cst}\end{aligned}$ & $2 \mathrm{~B}$ & 38.80 \\
\hline IV & 66.16 & 2.36 & $\begin{aligned} K(2 n=28)= & 2 \mathrm{Am}+16 \mathrm{Bm}+2 \mathrm{Bsm}+2 \mathrm{Bst} \\
& +4 \mathrm{Cm}+2 \mathrm{Cst}\end{aligned}$ & $2 \mathrm{~A}$ & 38.06 \\
\hline $\mathrm{V}$ & 72.64 & 2.39 & $\begin{aligned} \mathrm{K}(2 \mathrm{n}=28)= & 2 \mathrm{Am}+2 \mathrm{Ast}+4 \mathrm{Bm}+12 \mathrm{Bsm} \\
& +6 \mathrm{Bst}+2 \mathrm{Cst}\end{aligned}$ & 2B & 30.95 \\
\hline
\end{tabular}

$\mathrm{TCL}=$ Total Chromosome Length, $\mathrm{ACL}=$ Average Chromosome Length

\section{Discussion}

The data on the five diploid morphotypes of taro reported here show that Morphotypes IIV was similar in gross karyomorphology. However, in finer details they differed one from the other in respect of morphology of a few individual chromosomes. In Morphotype I, chromosomes No. 3 exhibited structural heteromorphism with respect to centromere position (Fig. 1), and this could be the result of pericentric inversion taken place in one of the members. In Morphotype II the largest pair exhibited size heteromorphism possibly brought about by deletion of a sizeable segment of the long arm (Fig. 2) in one of the members. Chromosome numbers $2,4,5,8$ and 9 in all the four morphotypes showed more or less comparable $r$-values, while the other chromosomes exhibited notable differences in centromeric location (Fig. 6). In Morphotype II, chromosomes 10, 11 and 14, and in Morphotype III chromosomes 11, 12,13 and 14 exhibited higher r-values. In Morphotype IV, chromosome No. 3 has strikingly higher ' $r$ ' value (4.7) as against 2 or less in Morphotype I-III. The difference in the r-values of these chromosomes should be the result of differential deletion of parts of short arms in the respective chromosomes. The data of karyomorphology presented here apparently indicates that the karyotype of Morphotype $\mathrm{V}$ is strikingly different from the other 

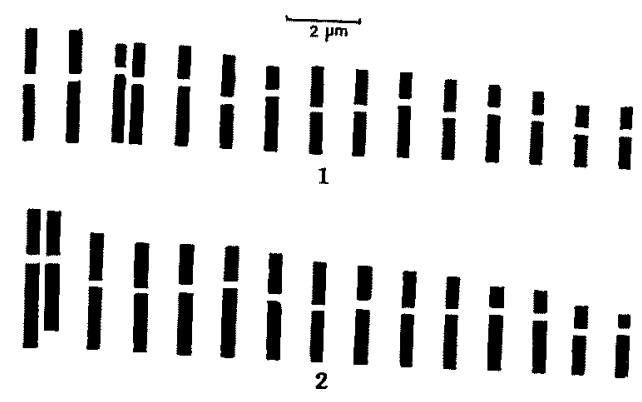

IHilibilitio

libitititioi

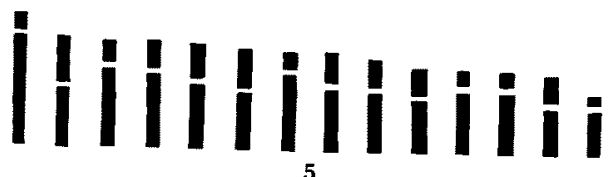

Figs. 1-5. Idiograms of five morphotypes of taro. 1, Idiogram of Morphotype I. 2, Idiogram of Morphotype II. 3, Idiogram of Morphotype III. 4, Idiogram of Morphotype IV. 5, Idiogram of Morphotype V.

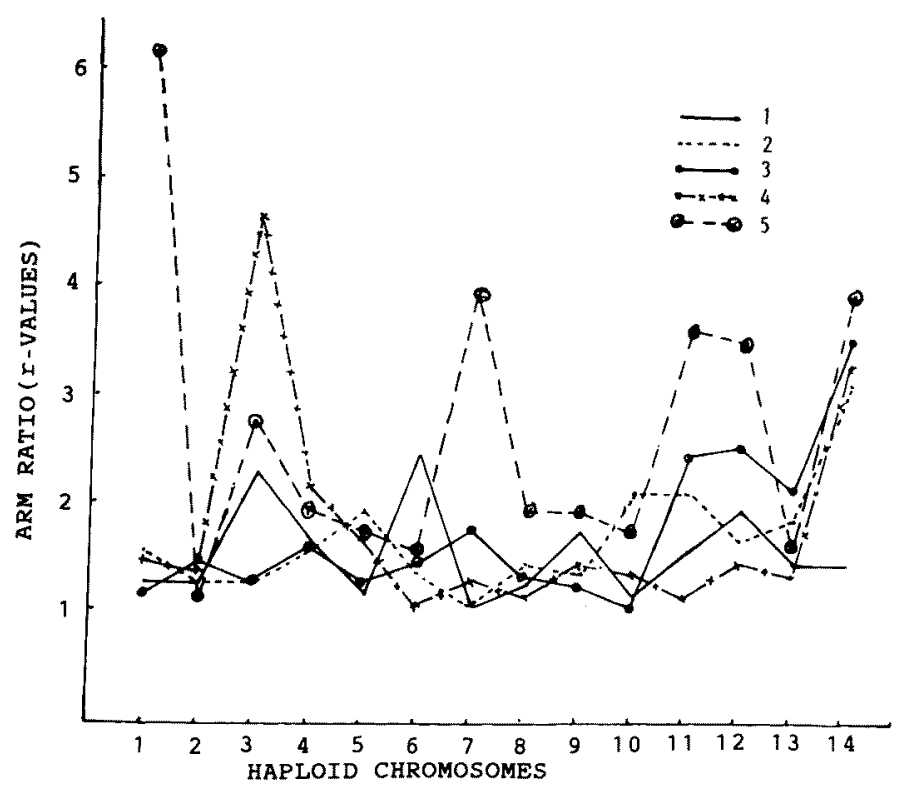

Fig. 6. Arm ratio of five morphotypes of taro. 
four in as much as it is chracterised by notable reduction in the frequency of m-type chromosomes ( 3 pairs as against 8 or above in the others) and striking predominance of st-type chromosomes ( 5 pairs as against 1 or 2 in the others). Chromosome No. 1 is strikingly different with $r=6.3$ as against less than 2 in all the other four morphotypes.

The existence of the degree of difference in the morphology of different individual chromosomes noticed between and among the different varieties of taro reported here not only provides a cytological basis for the plant morphological difference evident among them, but also shed light on the probable pattern of intraspecific karyotype variation within this species complex. The evidence is suggestive of gene rearrangements through chromosomal structural alterations having had played some role in the evolution of such morphologically diverse varieties in this species complex. In this connection, the difference in the gross karyomorphology noticed between Morphotype V on one hand and Morphotypes I-IV on the other is striking. The karyotype of Morphotype $\mathrm{V}$ appears to stand out from those of the others, and this is interesting from the taxonomic stand point.

\section{Summary}

Detailed karyomorphology of five morphotypes of taro is reported. Although in gross karyomorphology Morphotypes I-IV were similar, with respect to finer details of morphology of certain individual chromosomes, recognisable difference was noticed between and among them. Between Morphotypes I-IV and Morphotype V there was striking difference in karyomorphology, particularly in the frequency of $\mathrm{m}$ - and st-type chromosomes.

The degree of karyotype difference noticed is pointed out to shed light on the possible role of intraspecific karyotype changes and its bearing on the plant morphological difference evident in the species complex. The gross karyomorphological difference noticed between Morphotype $\mathrm{V}$ and the others is pointed out to be of taxonomic implication.

\section{Acknowledgement}

One of the authors (MTS) is thankful to Dr. G. G. Nayar, Director, CTCRI, Trivandrum for granting study leave.

\section{References}

Coates, D. J., Yen, D. E. and Gaffey, P. M. 1988. Chromosome variation in Taro, Colocasia esculenta. Implications for origin in the Pacific. Cytologia 53: 551-560.

Huziwara, Y. 1962. The karyotype analysis in some genera of Compositae. IX The chromosome of some European species of Aster. Bot. Mag. 75: 143-150.

Kuruvilla, K. M. and Singh, A. 1981. Karyotypic and electrophoretic studies on taro and its origin. Euphytica 30: $405-413$.

Levan, A., Fredga, K. and Sandberg, A. A. 1964. Nomenclature for centromeric positions on chromosomes. Hereditas 52: 201-220.

Onwueme, I. C. 1978. The Tropical Tuber Crops. John Wiley and Sons 21: 199-225.

Sreekumari, M. T. and Mathew, P. M. 1989. Karyomorphology of six cultivars of taro (Colocasia esculenta Schott). New Botanist 16(1-4) 127-135.

Stebbins, G. L. 1958. Longivity, habitat and release of genetic variability in higher plants. Cold Spring Harb. Symp. Quart. Biol. 23 : 365-378. 